\title{
Enhanced photocatalytic degradation of tetracycline hydrochloride by molecular imprinted film modified $\mathrm{TiO}_{2}$ nanotubes
}

\author{
WANG HongTao, WU Xuan, ZHAO HuiMin* \& QUAN Xie \\ Key Laboratory of Industrial Ecology and Environmental Engineering, Ministry of Education, School of Environmental Science and Technology, \\ Dalian University of Technology, Dalian 116024, China
}

Received February 25, 2011; accepted October 21, 2011

\begin{abstract}
To enhance the photocatalytic activity of $\mathrm{TiO}_{2}$ nanotubes, tetracycline hydrochloride (TC) molecularly imprinted titania modified $\mathrm{TiO}_{2}$ nanotubes $\left(\mathrm{MIP}-\mathrm{TiO}_{2}\right.$ ) was prepared by liquid phase deposition, which improved the molecular recognition ability of the

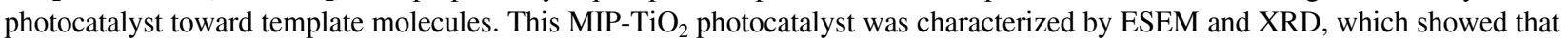
the imprinted titania was deposited on the nanotube uniformly and was of well-crystalized anatase-type. In the adsorption experiments, $\mathrm{MIP}-\mathrm{TiO}_{2}$ exhibited a high adsorption capacity (about 1.6 times higher than that of $\mathrm{TiO}_{2}$ nanotubes) for TC mainly because of its imprinted sites and high surface area. Under UV irradiation $\mathrm{MIP}^{-\mathrm{TiO}_{2}}$ showed enhanced photocatalytic activity with an apparent first-order rate constant 1.9 -fold that of $\mathrm{TiO}_{2}$ nanotubes.
\end{abstract}

liquid phase deposition (LPD), photocatalytic, molecularly imprinting, tetracycline hydrochloride

Citation: Wang H T, Wu X, Zhao $\mathrm{H} \mathrm{M}$, et al. Enhanced photocatalytic degradation of tetracycline hydrochloride by molecular imprinted film modified TiO nanotubes. Chin Sci Bull, 2012, 57: 601-605, doi: 10.1007/s11434-011-4897-x

$\mathrm{TiO}_{2}$ has been widely studied for environmental protection applications because of its high photocatalytic (PC) activity, chemical stability, nontoxicity and relatively low price. Many organic pollutants such as persistent toxic substances (PTS), dyes, pesticides and herbicides are degraded by $\mathrm{TiO}_{2}$ catalysts under UV light irradiation [1-4]. Titania nanotubes can improve the photocatalytic properties compared with other forms of titania because of its excellent PC activity $[5,6]$. In previous studies, $\mathrm{TiO}_{2}$ nanotubes prepared by electrochemical anodic oxidation exhibited high PC and photoelectrocatalytic activity during organic pollutant degradation [7]. Their well-formed nanotube array architecture offers the ability to influence the absorption and propagation of light through the architecture and the closely packed vertically aligned crystalline tubes also offer excellent electron percolation pathways for vectorial charge transfer between the interfaces [8-10]. However, PC efficiency still does not fulfill the requirements for practical application in the

*Corresponding author (email: zhaohuim@dlut.edu.cn) treatment of low-level harmful pollutants. The efficiency of $\mathrm{TiO}_{2}$ photocatalysts for application in wastewater treatment needs to increase.

Molecular imprinting is a promising technique for creating specific molecular recognition sites in solid materials by employing target molecule as a template [11,12]. Since Vlatakis et al. [13] reported theophylline and diazepam molecularly imprinted polymers (MIPs) for mimicking antibody combining sites, interest in the molecularly imprinting technique has increased because of its unique properties of predetermination, selectivity and specific affinity for templates [14-16]. Recently, Shen et al. [17,18] developed a new way to enhance the PC efficiency of $\mathrm{TiO}_{2}$ nanoparticles by imprinting the target molecule onto a photocatalyst's surface. In our previous work, we found that the photoelectrocatalysis of $\mathrm{TiO}_{2}$ nanotubes could also be improved and selectivity could be realized by modification with organic imprinted polymers on the substrate of the $\mathrm{TiO}_{2}$ nanotubes [19]. With the development of molecular imprinting technology, inorganic materials have been preferred for applica- 
tions because of their stability. $\mathrm{TiO}_{2}$ molecularly imprinted thin layers prepared by liquid phase deposition (LPD) or solgel methods show good sensitivity and selectivity for the detection or electrocatalysis of template molecules [20-22]. The preparation procedure of these materials is simple and they are more stable than organic materials. Accordingly, surface molecularly imprinted titania coated onto $\mathrm{TiO}_{2}$ nanotubes is accessible for the construction of novel hybrid photocatalysis, which retains the specific adsorption ability of the imprinted network and the high PC activity of the nanotubes.

In this study, surface molecularly imprinted titania was prepared on $\mathrm{TiO}_{2}$ nanotubes by the liquid phase deposition method. Tetracycline hydrochloride (TC, Figure 1) was used as a template and it is a type of broad-spectrum antibiotics that is used in pharmaceuticals and personal care products (PPCPs). The abuse of TC and other antibacterials in aquaculture and farming industry negatively affects the environment and antibiotic residues in water and food results in allergies in humans. The photocatalytic activity of the fabricated $\mathrm{MIP}-\mathrm{TiO}_{2}$ was found to be higher than that of $\mathrm{TiO}_{2}$ nanotubes.

\section{Experimental}

\subsection{Chemicals and materials}

Titanium sheets were purchased from Tianjin Gerui Co. Ltd. Tetracycline hydrochloride (TC) was obtained from Johnson Matthey. $\left(\mathrm{NH}_{4}\right) \mathrm{TiF}_{6}$ was from Tianjin Fuchen Chemical Reagent Co. $\mathrm{H}_{3} \mathrm{BO}_{3}$ was from Shenyang NO.5 Chemical Reagent Factory. All the other chemicals were of analytical grade and used as received. Ultrapure water was used for the preparation of all aqueous solutions.

\subsection{Preparation of the $\mathrm{TiO}_{2}$ nanotubes}

The $\mathrm{TiO}_{2}$ nanotubes were prepared by anodic oxidation according to literature in a two-electrode electrochemical cell [7]. To induce crystallinity, the initially amorphous asanodized layers were annealed at $500^{\circ} \mathrm{C}$ for $2 \mathrm{~h}$ at a rate of $3^{\circ} \mathrm{C} / \mathrm{min}$ during the heating processes and then cooled to

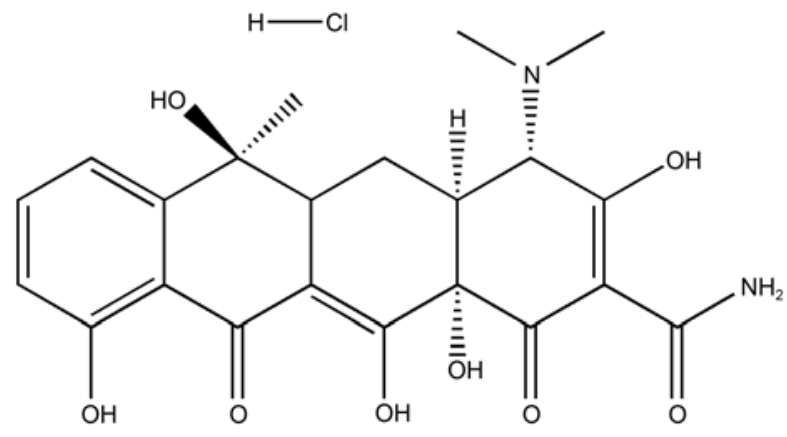

Figure 1 Chemical structure of tetracycline hydrochloride. room temperature at a rate of $3^{\circ} \mathrm{C} / \mathrm{min}$

\subsection{Synthesis of imprinted titania modified $\mathrm{TiO}_{2}$ nanotubes}

The liquid phase deposition of imprinted titania onto the $\mathrm{TiO}_{2}$ nanotubes was carried out by mixing $5 \mathrm{~mL} 0.1 \mathrm{~mol} / \mathrm{L}$ $\left(\mathrm{NH}_{4}\right)_{2} \mathrm{TiF}_{6}$ with $5 \mathrm{~mL} 0.3 \mathrm{~mol} / \mathrm{L} \mathrm{H}_{3} \mathrm{BO}_{3}$ followed by adding $10 \mathrm{mg}$ of TC. The $\mathrm{TiO}_{2}$ nanotube substrate was placed vertically into the deposition solution and the temperature was maintained at $20^{\circ} \mathrm{C}$ in a water-bath for a certain deposition time. Molecularly imprinted titania modified $\mathrm{TiO}_{2}$ nanotubes $\left(\mathrm{MIP}^{-\mathrm{TiO}_{2}}\right)$ were thus prepared after the template molecule was removed by thoroughly rinsing with water. Non-imprinted $\mathrm{TiO}_{2}$ nanotubes $\left(\mathrm{LPD}-\mathrm{TiO}_{2}\right)$ were used as a control sample and were prepared by the same method but in the absence of TC in the deposition solution and the same procedures were used as for $\mathrm{MIP}-\mathrm{TiO}_{2}$.

\subsection{Characterization and photocatalytic experiments}

The morphological characterization of the samples was carried out using an environmental scanning electron microscope (ESEM; Quanta 200 FEG). X-ray diffraction (XRD) analysis was carried out using a diffractometer with $\mathrm{Cu} \mathrm{K} \alpha$ radiation (Shimadzu LabX XRD-6000) to determine the crystalline structure of the samples.

The adsorption of TC onto $\mathrm{LPD}-\mathrm{TiO}_{2}$ and $\mathrm{MIP}-\mathrm{TiO}_{2}$ was performed by placing the sample in solutions containing $20 \mathrm{mg} / \mathrm{L}$ TC. The whole process was carried out with continuous magnetic stirring for $2 \mathrm{~h}$ at $20^{\circ} \mathrm{C}$ in a water bath. The amount of adsorbed TC was determined by measuring the difference between the total amount of TC and the residual amount in solution.

The photocatalytic oxidation of TC was carried out in a single quartz photochemical reactor. The lamp was placed vertically outside the reactor with an illumination intensity of $1.0 \mathrm{~mW} / \mathrm{cm}^{2}$. All experiments were carried out with continuous magnetic stirring. The TC aqueous solution with an initial concentration of $20 \mathrm{mg} / \mathrm{L}$ was sampled periodically during the reaction and the absorbance was measured at $275 \mathrm{~nm}$ as a function of reaction time using a UV-7504 spectrophotometer.

\section{Discussion}

\subsection{Mechanism of the LPD procedure}

Liquid phase deposition is a soft-wet chemical and selfassembling process for the preparation of oxide films. The principle of the LPD process is the formation of oxide thin films by the slow hydrolysis of a metal-fluoro complex by fluoride scavengers $[6,21,23] .\left[\mathrm{TiF}_{6}\right]^{2-}$ is hydrolyzed to $\left[\mathrm{TiF}_{6-n}(\mathrm{OH})_{n}\right]^{2-}$ groups and HF molecules. The hydrolysis accelerates after $\mathrm{HF}$ is captured by $\mathrm{H}_{3} \mathrm{BO}_{3}$. A mechanism 
for the preparation of the $\mathrm{LPD}-\mathrm{TiO}_{2}$ film can be expressed as the reactions (1) and (2). After the consumption of $F$ in $\left[\mathrm{TiF}_{6-n}(\mathrm{OH})_{n}\right]^{2-},\left[\mathrm{Ti}(\mathrm{OH})_{6}\right]^{2-}$ is formed in solution. The formation of a - Ti-O-Ti- structure is achieved upon the loss of a water molecule from $\left[\mathrm{Ti}(\mathrm{OH})_{6}\right]^{2-}$.

$$
\begin{aligned}
{\left[\mathrm{TiF}_{6}\right]^{2-}+n \mathrm{H}_{2} \mathrm{O} } & \rightarrow\left[\mathrm{TiF}_{6-n}(\mathrm{OH})_{n}\right]^{2-}+n \mathrm{HF} \\
\mathrm{H}_{3} \mathrm{BO}_{3}+4 \mathrm{HF} & \rightarrow \mathrm{HBF}_{4}+3 \mathrm{H}_{2} \mathrm{O}
\end{aligned}
$$

For the preparation of $\mathrm{MIP}^{-\mathrm{TiO}_{2}}$, the template can interact with $\left[\mathrm{TiF}_{6-n}(\mathrm{OH})_{n}\right]^{2-}$ groups and form noncovalent bonds with $\mathrm{TiO}_{2}$ molecules (Figure 2). To remove the loose imprinted material and the adsorbed $\mathrm{HBF}_{4}$ and $\mathrm{NH}_{4}^{+}$, MIP$\mathrm{TiO}_{2}$ was washed with water. MIP-TiO ${ }_{2}$ was then be used to rebind the TC molecules.

\subsection{Morphology of the imprinted titania modified $\mathrm{TiO}_{2}$ nanotubes}

Figure 3 shows top-view ESEM images of $\mathrm{TiO}_{2}$ nanotubes that were fabricated using $\mathrm{MIP}-\mathrm{TiO}_{2}$ over different deposited times and upon $\mathrm{LPD}-\mathrm{TiO}_{2}$ liquid phase deposition over 5 h. As shown in Figure 3(a), the diameter range of the $\mathrm{TiO}_{2}$ nanotubes is about 60 to $90 \mathrm{~nm}$ with wall thicknesses of about $20 \mathrm{~nm}$. After liquid phase deposition, the molecular imprinted titania film was uniformly deposited onto the surface of the $\mathrm{TiO}_{2}$ nanotubes. The film thickness increased with an increase in deposition time and simultaneously the inner radius decreased gradually (Figure 3(b)-(d)). For a deposition time of up to $21 \mathrm{~h}$ the whole $\mathrm{TiO}_{2}$ nanotubes surface was covered by the molecular imprinted titania film, and an obvious crack appeared because of the over-covered molecular imprinted titania film. Therefore, in this study the imprinted titania that was deposited for $5 \mathrm{~h}$ was chosen for further investigation to determine the requirements for a high photocatalysis efficiency. Based on a comparison between the morphology of $\mathrm{LPD}^{-\mathrm{TiO}_{2}}$ (Figure 3(f)) and MIP$\mathrm{TiO}_{2}$ (Figure 3(c)), which was deposited over $5 \mathrm{~h}$ it is reasonable to deduce that the template molecules that were added during the imprinting process had little influence on the morphology of the $\mathrm{MIP}_{-} \mathrm{TiO}_{2}$.

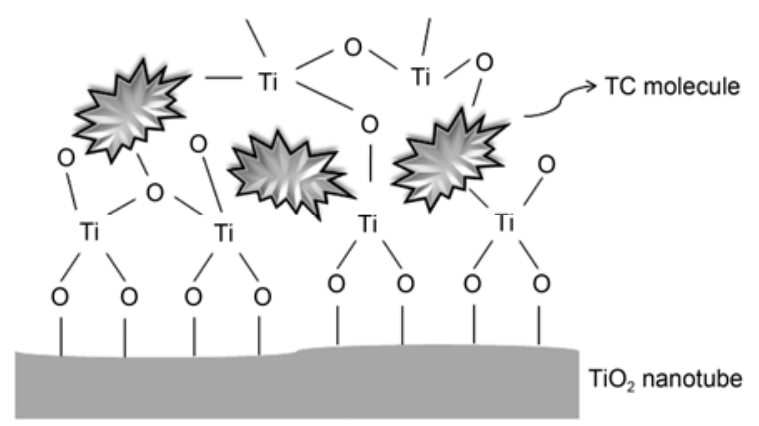

Figure 2 Schematic of a molecularly imprinted titania modified $\mathrm{TiO}_{2}$ nanotube $\left(\mathrm{MIP}-\mathrm{TiO}_{2}\right)$ formed by liquid phase deposition.
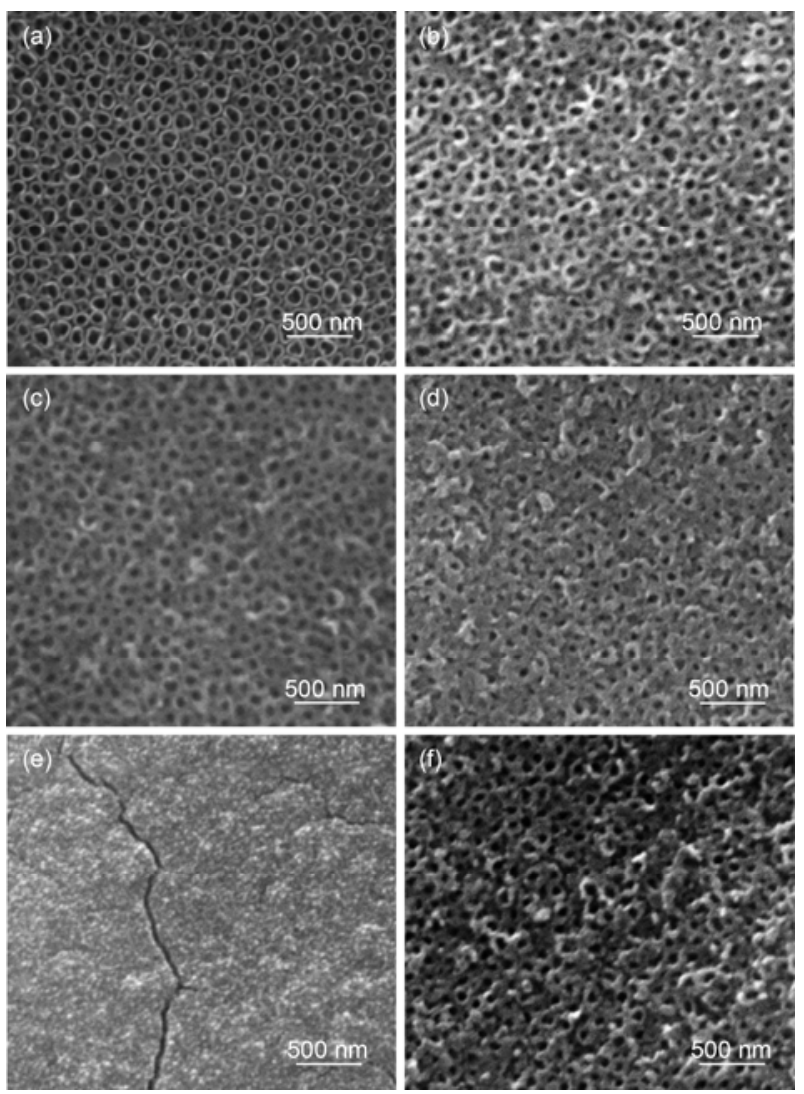

Figure 3 ESEM image of (a) $\mathrm{TiO}_{2}$ nanotubes and $\mathrm{MIP}_{-} \mathrm{TiO}_{2}$ deposition over (b) $3 \mathrm{~h}$, (c) $5 \mathrm{~h}$, (d) $7 \mathrm{~h}$ and (e) $21 \mathrm{~h}$, and (f) non-imprinted titania modified $\mathrm{TiO}_{2}$ nanotubes $\left(\mathrm{LPD}-\mathrm{TiO}_{2}\right.$ ) deposited over $5 \mathrm{~h}$.

\subsection{XRD analysis}

Figure 4 shows the XRD patterns obtained for the $\mathrm{TiO}_{2}$ nanotubes, $\mathrm{MIP}_{-} \mathrm{TiO}_{2}$ and $\mathrm{LPD}-\mathrm{TiO}_{2}$. Well-crystalized anatase-type $\mathrm{TiO}_{2}$ films without any other phase characteristics were formed on the $\mathrm{TiO}_{2}$ nanotubes after annealing at $500^{\circ} \mathrm{C}$. Both $\mathrm{MIP}-\mathrm{TiO}_{2}$ and $\mathrm{LPD}-\mathrm{TiO}_{2}$ are in anatase form. Neither contains the rutile phase, which is a polymorph that is less

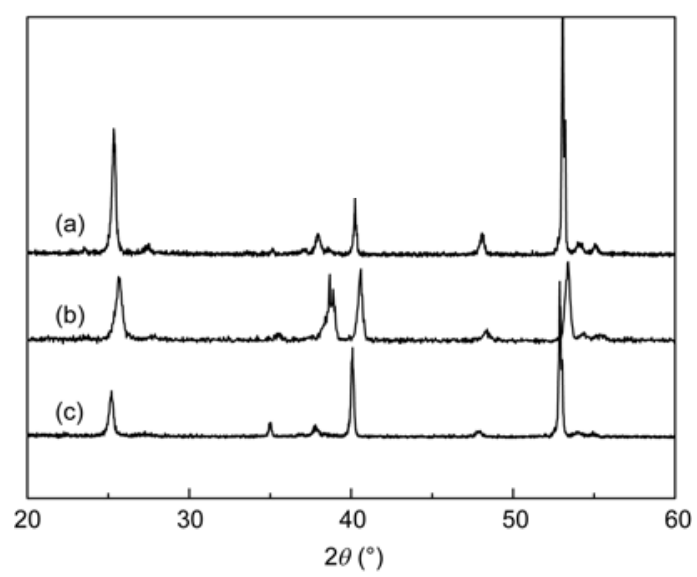

Figure 4 XRD analysis of (a) $\mathrm{TiO}_{2}$ nanotubes, (b) $\mathrm{MIP}_{-} \mathrm{TiO}_{2}$ and (c) $\mathrm{LPD}^{-\mathrm{TiO}_{2}}$ 
photoactive than anatase [24,25]. The strength of the peaks in the MIP-TiO ${ }_{2}$ and $\mathrm{LPD}-\mathrm{TiO}_{2}$ samples are a little weaker than that for $\mathrm{TiO}_{2}$ nanotubes, which is due to the loose density of the deposited samples. The XRD patterns indicate that a modification of the deposited layer on the $\mathrm{TiO}_{2}$ nanotubes does not affect its crystallization and its photocatalytic ability is retained.

\subsection{Adsorption properties of the $\mathrm{TiO}_{2}$ nanotubes, LPD- $\mathrm{TiO}_{2}$ and MIP-TiO}

The adsorption of TC onto $\mathrm{LPD}-\mathrm{TiO}_{2}$ and $\mathrm{MIP}-\mathrm{TiO}_{2}$ was performed by placing the sample in solutions containing $20 \mathrm{mg} / \mathrm{L} \mathrm{TC}$. The amount of adsorbed TC was determined by measuring the difference between the total amount of TC and the residual amount in solution. The adsorption ability of the $\mathrm{TiO}_{2}$ nanotubes for TC was determined under the same conditions. As shown in Table 1 the imprinting effect was confirmed by the fact that MIP-TiO ${ }_{2}$ showed a higher adsorption capacity for $\mathrm{TC}$ than the $\mathrm{TiO}_{2}$ nanotubes and LPD- $\mathrm{TiO}_{2}$. The maximum adsorption capacity under equilibrium conditions was about $1.3 \mathrm{ng}$ for the $20 \mathrm{mg} / \mathrm{L} \mathrm{TC}$ solution, which was 1.6 times higher than that of the $\mathrm{TiO}_{2}$ nanotubes and 1.2 times of $\mathrm{LPD}-\mathrm{TiO}_{2}$. The effective imprinted sites of the MIP-TiO $\mathrm{T}_{2}$ that was produced at the wall or the inner surface of the nanotubes contributed to the improved adsorption capacity for the target molecule. It is expect that $\mathrm{MIP}-\mathrm{TiO}_{2}$ will have a high TC photodegradation efficiency.

\subsection{Photocatalytic activities}

The photocatalytic degradation of $\mathrm{TC}$ by $\mathrm{TiO}_{2}$ nanotubes, LPD-TiO 2 and $\mathrm{MIP}_{2} \mathrm{TiO}_{2}$ was determined under UV light irradiation. The results are shown in Figure 5. The PC removals of TC for $\mathrm{LPD}-\mathrm{TiO}_{2}$ and $\mathrm{MIP}-\mathrm{TiO}_{2}$ are much higher than that for the $\mathrm{TiO}_{2}$ nanotubes (Figure 5(a)). The kinetics of TC degradation in this study for the direct photolysis (DP) and photocatalytic degradation by the $\mathrm{TiO}_{2}$ nanotubes, LPD-TiO 2 and $\mathrm{MIP}-\mathrm{TiO}_{2}$ follows pseudo first order kinetics, as shown in Figure 5(b). The apparent first-order rate constant $k$ was evaluated according to $\ln \left(C_{0} / C\right)=k t$, where $C$ represents the TC concentration at time $t$ and $C_{0}$ is the initial concentration. The corresponding kinetic constants and regression coefficients of TC by direct photocatalysis and photocatalysis by $\mathrm{TiO}_{2}, \mathrm{LPD}-\mathrm{TiO}_{2}$ and $\mathrm{MIP}-\mathrm{TiO}_{2}$ are also given in Figure 5(b). The presence of $\mathrm{LPD}^{-\mathrm{TiO}_{2}}$ and MIP-

Table 1 Amounts of TC adsorbed by the $\mathrm{TiO}_{2}$ nanotubes, LPD- $\mathrm{TiO}_{2}$ and $\mathrm{MIP}-\mathrm{TiO}_{2}$ at $20^{\circ} \mathrm{C}$ over $2 \mathrm{~h}$

\begin{tabular}{cccc}
\hline \multirow{2}{*}{$C(\mathrm{mg} / \mathrm{L})$} & \multicolumn{3}{c}{ Adsorption of TC (ng) } \\
\cline { 2 - 4 } & $\mathrm{TiO}_{2}$ & $\mathrm{LPD}^{2} \mathrm{TiO}_{2}$ & ${\mathrm{MIP}-\mathrm{TiO}_{2}}$ \\
\hline 20 & 0.48 & 1.1 & 1.3 \\
\hline
\end{tabular}
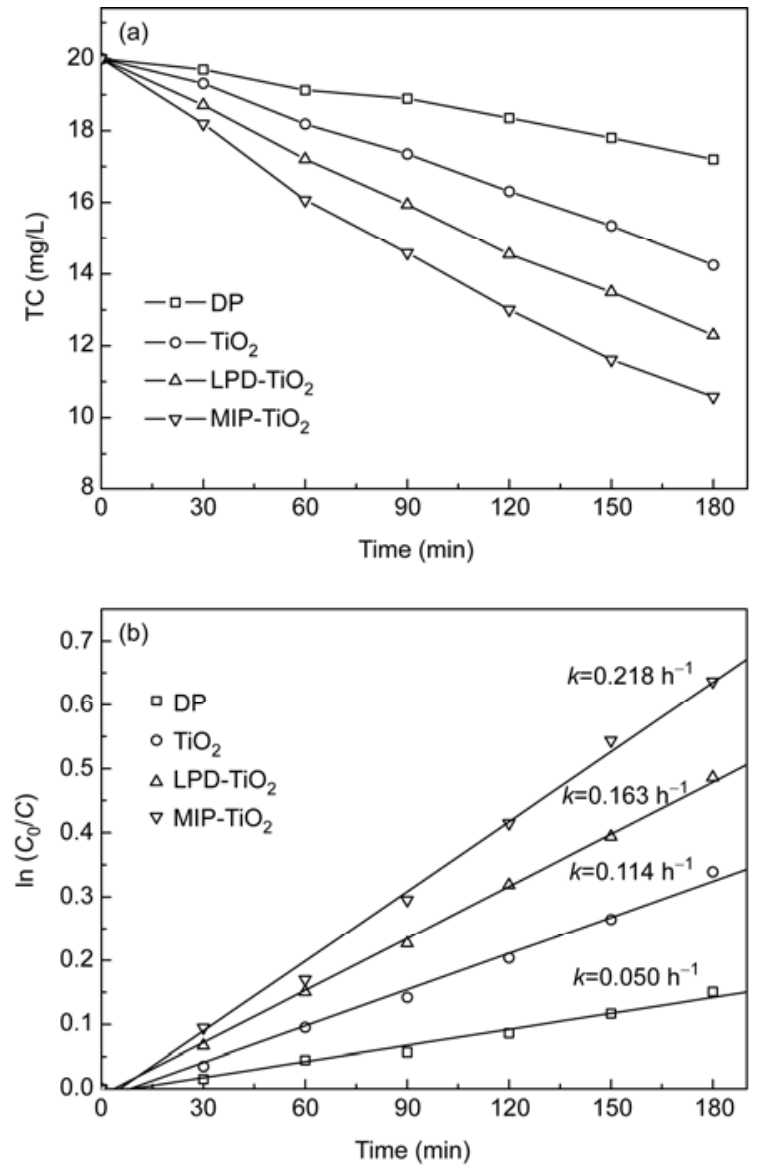

Figure 5 (a) Variation of TC concentrations and (b) variation of $\ln \left(C_{0} / C\right)$ with degradation time in the DP and PC processes involving $\mathrm{TiO}_{2}$ nanotubes, $\mathrm{LPD}-\mathrm{TiO}_{2}$ and $\mathrm{MIP}-\mathrm{TiO}_{2}$ with a TC concentration of $20 \mathrm{mg} / \mathrm{L}$.

$\mathrm{TiO}_{2}$ photocatalysts increases the rates of TC removal giving apparent constants of 0.163 and $0.218 \mathrm{~h}^{-1}$, respectively. The rate constant for TC photodegradation by $\mathrm{MIP}^{-\mathrm{TiO}_{2}}$ is about 1.9 times higher than that for the $\mathrm{TiO}_{2}$ nanotubes.

\section{Conclusions}

In conclusion, using $\mathrm{TC}$ as a template and $\mathrm{TiO}_{2}$ nanotubes as a support, a molecularly imprinted titania modified $\mathrm{TiO}_{2}$ photocatalyst was prepared by liquid phase deposition. A MIP layer provided specific molecular recognition sites leading to a high absorption ability towards the target pollutant. Photodegradation experiments confirmed that the photocatalytic activity of the $\mathrm{TiO}_{2}$ photocatalyst can be enhanced by combining molecularly imprinted titania with $\mathrm{TiO}_{2}$ nanotubes. This is an alternative way to increase the $\mathrm{PC}$ activity of $\mathrm{TiO}_{2}$ by a molecularly imprinted film fabricated by liquid phase deposition.

This work was supported by the National Natural Science Foundation of China (20877012), the National High Technology Research and Develop- 
ment Program of China (2007AA06Z406), the Program for New Century Excellent Talents in University (NCET-08-0079) and the Program for Changjiang Scholars and Innovative Research Team in University (IRT0813).

1 Sun B, Reddy E P, Smirniotis P G. Visible light Cr(VI) reduction and organic chemical oxidation by $\mathrm{TiO}_{2}$ photocatalysis. Environ Sci Technol, 2005, 39: 6251-6259

2 Tachikawa T, Fujitsuka M, Majima T. Mechanistic insight into the $\mathrm{TiO}_{2}$ photocatalytic reactions: Design of new photocatalysts. J Phys Chem C, 2007, 111: 5259-5275

3 Liu Z Y, Zhang X T, Nishimoto S, et al. Efficient photocatalytic degradation of gaseous acetaldehyde by highly ordered $\mathrm{TiO}_{2}$ nanotube arrays. Environ Sci Technol, 2008, 42: 8547-8551

4 Zheng R Y, Lin L, Xie J L, et al. State of doped phosphorus and its influence on the physicochemical and photocatalytic properties of $\mathrm{P}$ doped titania. J Phys Chem C, 2008, 112: 15502-15509

5 Mor G K, Varghese O K, Paulose M, et al. A review on highly ordered, vertically oriented $\mathrm{TiO}_{2}$ nanotube arrays: Fabrication, material properties, and solar energy applications. Sol Energ Mater Sol Cells, 2006, 90: 2011-2075

6 Zhang J D, Zheng Y Q, Jiang G D, et al. Electrocatalytic evaluation of liquid phase deposited methylene blue $/ \mathrm{TiO}_{2}$ hybrid films. Electrochem Comm, 2008, 10: 1038-1040

7 Quan X, Yang S G, Ruan X L, et al. Preparation of titania nanotubes and their environmental applications as electrode. Environ Sci Technol, 2005, 39: 3770-3775

8 Albu S P, Ghicov A, Macak J M, et al. Self-organized, free-standing $\mathrm{TiO}_{2}$ nanotube membrane for flow-through photocatalytic applications. Nano Lett, 2007, 7: 1286-1289

9 Frank A J, Kopidakis N, Lagemaat J. Electrons in nanostructured $\mathrm{TiO}_{2}$ solar cells: Transport, recombination and photovoltaic properties. Coord Chem Rev, 2004, 248: 1165-1179

10 Mor G K, Shankar K, Paulose M, et al. Use of highly-ordered $\mathrm{TiO}_{2}$ nanotube arrays in dye-sensitized solar cells. Nano Lett, 2006, 6: 215-218

11 Xie C G, Zhang Z P, Wang D P, et al. Surface molecular self-assembly strategy for TNT imprinting of polymer nanowire/nanotube arrays.
Anal Chem, 2006, 78: 8339-8346

12 Sibrian-Vazquez M, Spivak D A. Molecular imprinting made easy. J Am Chem Soc, 2004, 126: 7827-7833

13 Vlatakis G, Andersson L I, Müller R, et al. Drug assay using antibody mimics made by molecular imprinting. Nature, 1993, 361: 645-647

14 Sellergren B. Imprinted polymers with memory for small molecules, proteins, or crystals. Angew Chem Int Ed, 2000, 39: 1031-1037

15 Percival C J, Stanley S, Galle M, et al. Molecular-imprinted, polymer-coated quartz crystal microbalances for the detection of terpenes. Anal Chem, 2001, 73: 4225-4228

16 Haupt K, Mosbach K. Molecularly imprinted polymers and their use in biomimetic sensors. Chem Rev, 2000, 100: 2495-2504

17 Shen X T, Zhu L H, Liu G X, et al. Enhanced photocatalytic degradation and selective removal of nitrophenols by using surface molecular imprinted titania. Environ Sci Technol, 2008, 42: 1687-1692

18 Shen X T, Zhu L H, Li J, et al. Synthesis of molecular imprinted polymer coated photocatalysts with high selectivity. Chem Commun, 2007, 11: 1163-1165

$19 \mathrm{Lu} \mathrm{N}$, Chen S, Wang H T, et al. Synthesis of molecular imprinted polymer modified $\mathrm{TiO}_{2}$ nanotube array electrode and their photoelectrocatalytic activity. J Solid State Chem, 2008, 181: 2852-2858

20 Feng L, Liu Y J, Hu J M. Molecularly imprinted $\mathrm{TiO}_{2}$ thin film by liquid phase deposition for the determination of L-glutamic acid. Langmuir, 2004, 20: 1786-1790

21 Li C Y, Wang C F, Wang C H, et al. Development of a parathion sensor based on molecularly imprinted nano- $\mathrm{TiO}_{2}$ self-assembled film electrode. Sens Actuator B-Chem, 2006, 117: 166-171

22 Lahav M, Kharitonov A B, Katz O, et al. Tailored chemosensors for chloroaromatic acids using molecular imprinted $\mathrm{TiO}_{2}$ thin films on ion-sensitive field-effect transistors. Anal Chem, 2001, 73: 720-723

23 Niesen T P, De-Guire M R. Review: Deposition of ceramic thin films at low temperatures from aqueous solutions. Solid State Ion, 2002, 151: 61-68

24 Hoffmann M R, Martin S T, Choi W, et al. Environmental applications of semiconductor photocatalysis. Chem Rev, 1995, 95: 69-96

25 Zhao H M, Chen Y, Quan X, et al. Preparation of Zn-doped $\mathrm{TiO}_{2}$ nanotubes electrode and its application in pentachlorophenol photoelectrocatalytic degradation. Chin Sci Bull, 2007, 52: 1456-1461

Open Access This article is distributed under the terms of the Creative Commons Attribution License which permits any use, distribution, and reproduction in any medium, provided the original author(s) and source are credited. 